\title{
Retraction
}

\section{Retracted: Gelsolin Restores A $\beta$-Induced Alterations in Choroid Plexus Epithelium}

\section{BioMed Research International}

Received 27 March 2021; Accepted 27 March 2021; Published 3 May 2021

Copyright (c) 2021 BioMed Research International. This is an open access article distributed under the Creative Commons Attribution License, which permits unrestricted use, distribution, and reproduction in any medium, provided the original work is properly cited.

BioMed Research International has retracted the article titled "Gelsolin Restores A $\beta$-Induced Alterations in Choroid Plexus Epithelium" [1], due to concerns with duplicated figures as initially raised on PubPeer [2].

Figures 1(a) and 1(b) appear to be identical to Figure 1(a) in [3]. Additionally, in Figure 2, the control and $A \beta 1-42$ panels appear very similar to the control and $A \beta 1-42$ panels in Figure 5(e) [4].

Following an investigation into these concerns, the editorial board has recommended the retraction of the article. The authors do not agree to the retraction.

\section{References}

[1] T. Vargas, D. Antequera, C. Ugalde, C. Spuch, and E. Carro, "Gelsolin Restores A $\beta$-Induced Alterations in Choroid Plexus Epithelium," Journal of biomedicine \& biotechnology, vol. 2010, Article ID 805405, 7 pages, 2010.

[2] Gelsolin Restores, "A beta-induced alterations in choroid plexus epithelium," 2010, https://pubpeer.com/publications/3013 CD1C9181153A7A51DCF1F6F9B8.

[3] D. Antequera, T. Vargas, C. Ugalde et al., "Cytoplasmic gelsolin increases mitochondrial activity and reduces $\mathrm{A} \beta$ burden in a mouse model of Alzheimer's disease," Neurobiology of Disease, vol. 36, no. 1, pp. 42-50, 2009.

[4] T. Vargas, C. Ugalde, C. Spuch et al., "A $\beta$ accumulation in choroid plexus is associated with mitochondrial-induced apoptosis," Neurobiology of Aging, vol. 31, no. 9, pp. 1569-1581, 2010. 


\title{
Gelsolin Restores A $\beta$-Induced Alterations in Choroid Plexus Epithelium
}

\author{
Teo Vargas,,${ }^{1,2}$ Desiree Antequera, ${ }^{1,2}$ Cristina Ugalde, ${ }^{3,4}$ Carlos Spuch,, ${ }^{1,2}$ and Eva Carro ${ }^{1,2}$ \\ ${ }^{1}$ Neuroscience Laboratory, Research Center, Hospital 12 de Octubre, Avenida de Córdoba, 28041 Madrid, Spain \\ ${ }^{2}$ Neurodegenerative Diseases Biomedical Research Center (CIBERNED), Madrid, Spain \\ ${ }^{3}$ Mitochondrial Diseases Laboratory, Research Center, Hospital 12 de Octubre, 28041 Madrid, Spain \\ ${ }^{4}$ Rare Disorders Biomedical Research Center (CIBERER), Madrid, Spain \\ Correspondence should be addressed to Eva Carro, carroeva@yahoo.es \\ Received 30 June 2009; Accepted 19 January 2010 \\ Academic Editor: Amanda McCann
}

Copyright ( $\odot 2010$ Teo Vargas et al. This is an open access article distributed under the Creative Commons Attribution License, which permits unrestricted use, distribution, and reproduction in any medium, provided the original work is properly cited.

Histologically, Alzheimer's disease (AD) is characterized by senile plaques and cerebrovascular amyloid deposits. In previous studies we demonstrated that in $\mathrm{AD}$ patients, amyloid- $\beta(\mathrm{A} \beta)$ peptide also accumulates in choroid plexus, and that this process is associated with mitochondrial dysfunction and epithelial cell death. However, the molecular mechanisms underlying $A \beta$ accumulation at the choroid plexus epithelium remain unclear. $\mathrm{A} \beta$ clearance, from the brain to the blood, involves $\mathrm{A} \beta$ carrier proteins that bind to megalin, including gelsolin, a protein produced specifically by the choroid plexus epithelial cells. In this study, we show that treatment with gelsolin reduces $\mathrm{A} \beta$-induced cytoskeletal disruption of blood-cerebrospinal fluid (CSF) barrier at the choroid plexus. Additionally, our results demonstrate that gelsolin plays an important role in decreasing $\mathrm{A} \beta$-induced cytotoxicity by inhibiting nitric oxide production and apoptotic mitochondrial changes. Taken together, these findings make gelsolin an appealing tool for the prophylactic treatment of $\mathrm{AD}$.

\section{Introduction}

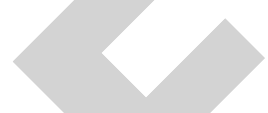

Alzheimer's disease (AD) is a neurodegenerative disorder characterized by a progressive loss of cognitive function and is associated with neuropathological hallmarks that include amyloid plaques, neurofibrillary tangles, synaptic loss, and neurodegeneration. Senile plaques mainly consist of an extracellular accumulation of the 40-42-aminoacid long peptide amyloid $\beta(\mathrm{A} \beta)[1,2]$, although intracellular deposits of $A \beta$ have also been reported $[3,4]$. Besides accumulating in the brain parenchyma, $\mathrm{A} \beta$ also accumulates in choroid plexus epithelial cells [5] and in cerebrovascular walls, where it induces blood-brain barrier disruption [6-8]. Several studies have shown that $\mathrm{A} \beta_{1-40}$ and $\mathrm{A} \beta_{1-42}$ alter transmembrane and cytoplasmic tight junction proteins in brain microvessel endothelial cells, including ZO-1, which ultimately leads to disruption in the integrity of the blood-brain barrier $[9,10]$.

In support of these findings, recent results from our laboratory have suggested direct relationship between $\mathrm{A} \beta$ accumulation at the choroid plexus epithelium and the development of functional and structural dysfunctions [5, 11]. In addition, we demonstrated the existence of a link between $\mathrm{A} \beta$-induced choroid plexus cell death, increased production of nitric oxide (NO), and mitochondrial dysfunction in the choroid plexus of patients with $\mathrm{AD}$ and amyloid precursor protein (APP)/PS1 mice [11].

The choroid plexus, which is made up of a single epithelial cell layer, is responsible for producing cerebrospinal fluid (CSF) and constitutes the blood-CSF barrier. Additionally, choroid plexus cells produce proteins involved in several processes important for normal brain function, such as prevention of $\mathrm{A} \beta$ fibrillization. One of such proteins is gelsolin [12], which is a potent actin-regulatory protein that controls cytoskeletal assembly and disassembly [13]. Gelsolin can be found both as an intrinsic cytoplasmic protein and as a secreted protein [14]. Besides controlling formation of cytoplasmic actin filaments, gelsolin plays an important role in apoptosis and amyloidosis. The secretory form of gelsolin is known to bind $\mathrm{A} \beta$ under normal physiological conditions [15], inhibit the fibrillation of $\mathrm{A} \beta$, and defibrillize preformed 
fibrils of this peptide [16]. Some groups have suggested that gelsolin could be used in the prophylactic treatment of $\mathrm{AD}$ as $\mathrm{A} \beta$ sequestering agent $[17,18]$.

In this study, we hypothesize that the secreted form of gelsolin could be an effective therapeutic approach for the preservation of blood-CSF barrier integrity and function, and thus an attractive tool for the prophylactic treatment of $\mathrm{AD}$. To test the hypothesis that secreted gelsolin can reduce $A \beta$ cytotoxicity on choroid plexus epithelium, we analyzed cytoskeletal alterations, including the distribution and expression of $\mathrm{ZO}-1$. In addition, we assessed $\mathrm{A} \beta$-induced NO production, cell death, and mitochondrial changes in choroid plexus epithelial cells.

\section{Methods}

Cell Culture. Epithelial cell monolayers from P3-P5 Wistar rats were prepared as described previously [19]. Cells were grown to confluence for 5-7 days and serum starved for 2 hours. Human analog peptides corresponding to $A \beta_{1-40}$, $\mathrm{A} \beta_{1-42}$, or scrambled $\mathrm{A} \beta_{1-42}(5 \mu \mathrm{g} / \mathrm{mL}$; AnaSpec, Inc.), and gelsolin, extracted from bovine plasma $(5 \mu \mathrm{g} / \mathrm{mL}$; Sigma), were added. Forty-eight hours after stimulation, cells were either fixed for immunocytochemical analysis or homogenized for immunoblot determination.

Antibodies. The following antibodies were used: mouse monoclonal anti-A $\beta_{1-40}$ (Chemicon), rabbit polyclonal anti$\mathrm{A} \beta_{1-42}$ (Chemicon), goat polyclonal anti-megalin (Santa Cruz Biotechnology), mouse monoclonal anti-gelsolin (Sigma), mouse monoclonal anti-pSer (Sigma), goat polyclonal anti-ZO-1 (Santa Cruz Biotechnology), mouse monoclonal anti-CoxVa (Molecular Probes), BIODIPY FL phallacidin (Invitrogen), Alexa-coupled (Molecular Probes), and HRP-conjugated (Bio-Rad).

Western-Blot Analysis. Western-blot (WB) analysis and immunoprecipitation were performed as described previously [19]. WB membranes were reblotted with the same antibody used for immunoprecipitation, and to normalize for protein load. Densitometric analysis was performed using ImageJ software (NIH). Nonimmune normal rabbit serum was used as a control for immunoprecipitation studies.

Blue Native Electrophoresis. Mitochondrial membranes were isolated according to the method described by Nijtmans et al. [20]. Enzyme activity of mitochondrial complexes from choroid plexus epithelial cell cultures was measured as described previously [11]. Gels were washed in distilled water, scanned, photographed immediately, and quantified with the aid of ImageJ software (NIH) [11].

Determination of NO Production. For NO detection, choroid plexus epithelial cell cultures were processed using the Nitric Oxide Colorimetric Assay Kit (BioVision, Inc.) as described previously [11].
Cell Death Quantification. After 48-hour incubations with $\mathrm{A} \beta_{1-42}$ and gelsolin, DNA fragmentation in choroid plexus epithelial cells undergoing apoptosis was detected with a Cell Death Detection ELISA ${ }^{\text {PLUS }}$ kit (Roche) as described previously [11].

\section{Results}

Gelsolin Binds to Megalin and Forms a Complex with $A \beta$. We observed that megalin from rat choroid plexus cells binds to $\mathrm{A} \beta_{1-40}$ and to gelsolin (Figure 1(a)). Furthermore, our results indicate that both the cytoplasmic and the secreted forms of gelsolin bind to megalin (Figure 1(a), top panel). These findings were corroborated by imunoprecipitation and double immunostaining, which showed that gelsolin colocalizes with megalin and $A \beta$ in choroid plexus epithelial cells (Figure 1(b)).

Gelsolin Inhibits A $\beta$-Induced Disruption on Choroid Plexus Epithelial Cell Cytoskeleton. Choroid plexus epithelial cells exposed to $A \beta_{1-42}$ for 48 hours showed a disrupted plasma membrane pattern of ZO- 1 with relocation of this protein to the cytoplasm (Figure 2(a)). A $\beta_{1-42}$-induced disruption of epithelial barrier integrity was also confirmed by an increase on serine phosphorylation rate. Immunoprecipitation with anti-ZO-1, followed by immunoblotting with antipSer, showed an increase in serine ZO-1 phosphorylation and a reduction in ZO-1 expression in choroid plexus epithelial cells (Figure 2(b)). We found that coadministration of gelsolin restored these $A \beta_{1-42}$-induced effects (Figures $2(\mathrm{a})$ and $2(\mathrm{~b}))$. Moreover, this $\mathrm{A} \beta_{1-42}$-induced effect on the behavior of this tight junction protein was also accompanied by cytoskeletal disruption, as we observed the formation actin stress fibers (Figure 2(c), middle panel). The immunocytochemical analysis revealed a restoration of cytoskeletal assembly when gelsolin was added to the culture medium (Figure 2(c), right panel).

Gelsolin Inhibits A $\beta$-Induced NO Production and Neuronal Death in Choroid Plexus Epithelial Cells. Gelsolin blocked $\mathrm{A} \beta_{1-42}$-induced NO production by cultured choroid plexus epithelial cells after 48 hours of treatment (Figure 3(a)). In vitro, $A \beta_{1-42}$-induced cell death in choroid plexus epithelial cells was also reversed after 48 hours of gelsolin administration (Figure 3(b)).

Gelsolin Increases Mitochondrial Respiratory Chain Activity in Choroid Plexus Epithelial Cells. When gelsolin was added to the choroid plexus culture, an increased activity of complex IV was observed as compared with control cells (Figure 3(c)). Moreover, gelsolin was able to reverse the inhibitory effect of $\mathrm{A} \beta$ in complex IV activity (Figure 3(c)). WB performed to assess protein level alterations revealed a parallel activation in complex IV, reflected by an increase in Cox Va subunit levels (Figure 3(c)). 

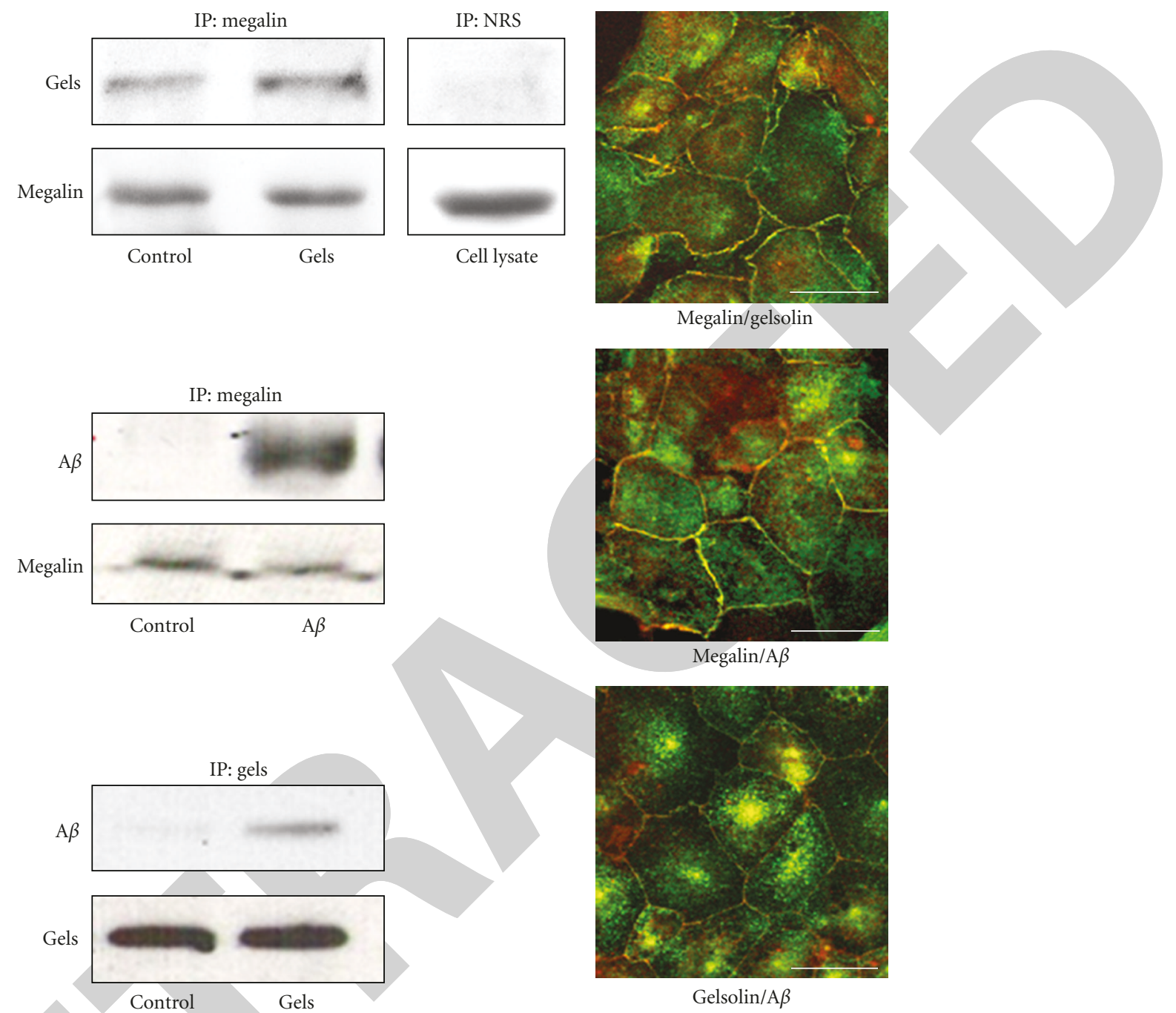

(a)

(b)

FIGURE 1: Gelsolin expression in choroid plexus epithelial cells. (a) Antimegalin immunoprecipitation of rat choroid plexus cell extracts, followed by blotting with respective antibodies, revealed an association between megalin, endogenous gelsolin, the exogenously added secreted gelsolin form, and the exogenously added $\mathrm{A} \beta$. Immunoprecipitation with nonspecific serum showed no unspecific $\mathrm{A} \beta$ association. Binding of gelsolin with exogenously added $\mathrm{A} \beta$ was also observed. Representative blots are shown $(n=4)$. (b) Megalin colocalized with gelsolin and exogenously added $\mathrm{A} \beta$ in choroid plexus cultures. Confocal images also show gelsolin colocalization with $\mathrm{A} \beta$. Scale bars $=$ $10 \mu \mathrm{m}$. IP: Immunoprecipitation; NRS: normal rabbit serum.

\section{Discussion}

Gelsolin, an actin-regulatory protein, exists both as an intracellular and extracellular protein [14] and is present in all nervous system cell types, including neurons [21] and choroid plexus [12]. Our findings indicate that secreted gelsolin is involved in the pathology of $\mathrm{AD}$ through the regulation of brain $\mathrm{A} \beta$ and its neurotoxic effects. Plasma gelsolin has been found to bind and reduce brain $\mathrm{A} \beta$ $[15,17,18]$. In the present study we had confirmed the formation of a complex between cytoplasmic and secreted gelsolin with $\mathrm{A} \beta$, accordingly with previously published studies $[15,22]$. Our current results extend these observations, suggesting that megalin, an endocytic receptor involved in $\mathrm{A} \beta$ clearance [23-27], has a functional role in the formation of this complex. We show that megalin binds $\mathrm{A} \beta$ /gelsolin complex in the choroid plexus epithelium, suggesting a role in clearance of $\mathrm{A} \beta$ from CSF to the blood. The latter is not surprising in view of megalin's ability to transport a large variety of proteins [28].

Abnormalities in cytoskeletal organization are a common feature of many neurodegenerative disorders, including AD. Interestingly, $\mathrm{A} \beta_{1-42}$-induced cytoskeletal alterations known to be associated with the proteolytic degradation of the tight junction-associated protein $\mathrm{ZO}-1[10,11]$ were reversed after secreted gelsolin treatment, with relocation from the cytoplasm to the original position in the cell membrane of choroid plexus epithelial cells. In addition, our results suggest 

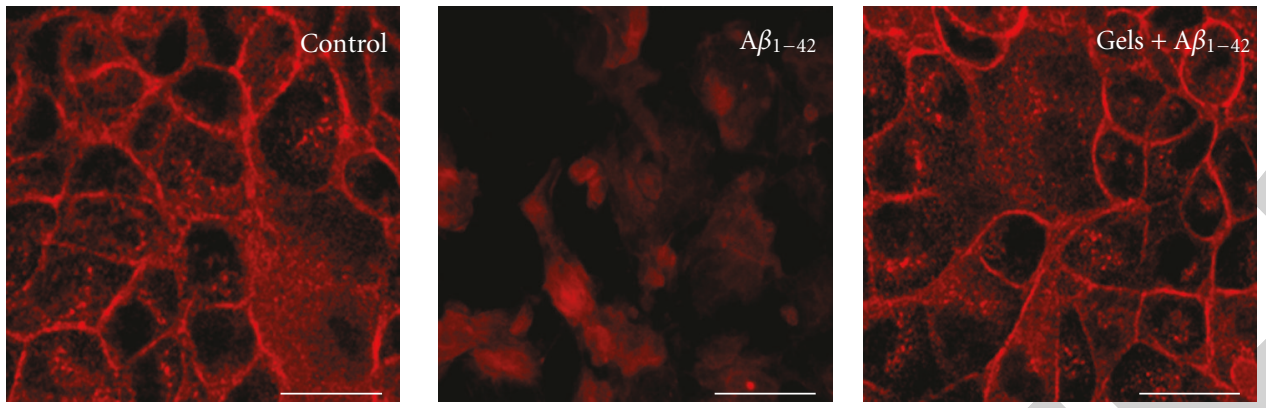

(a)
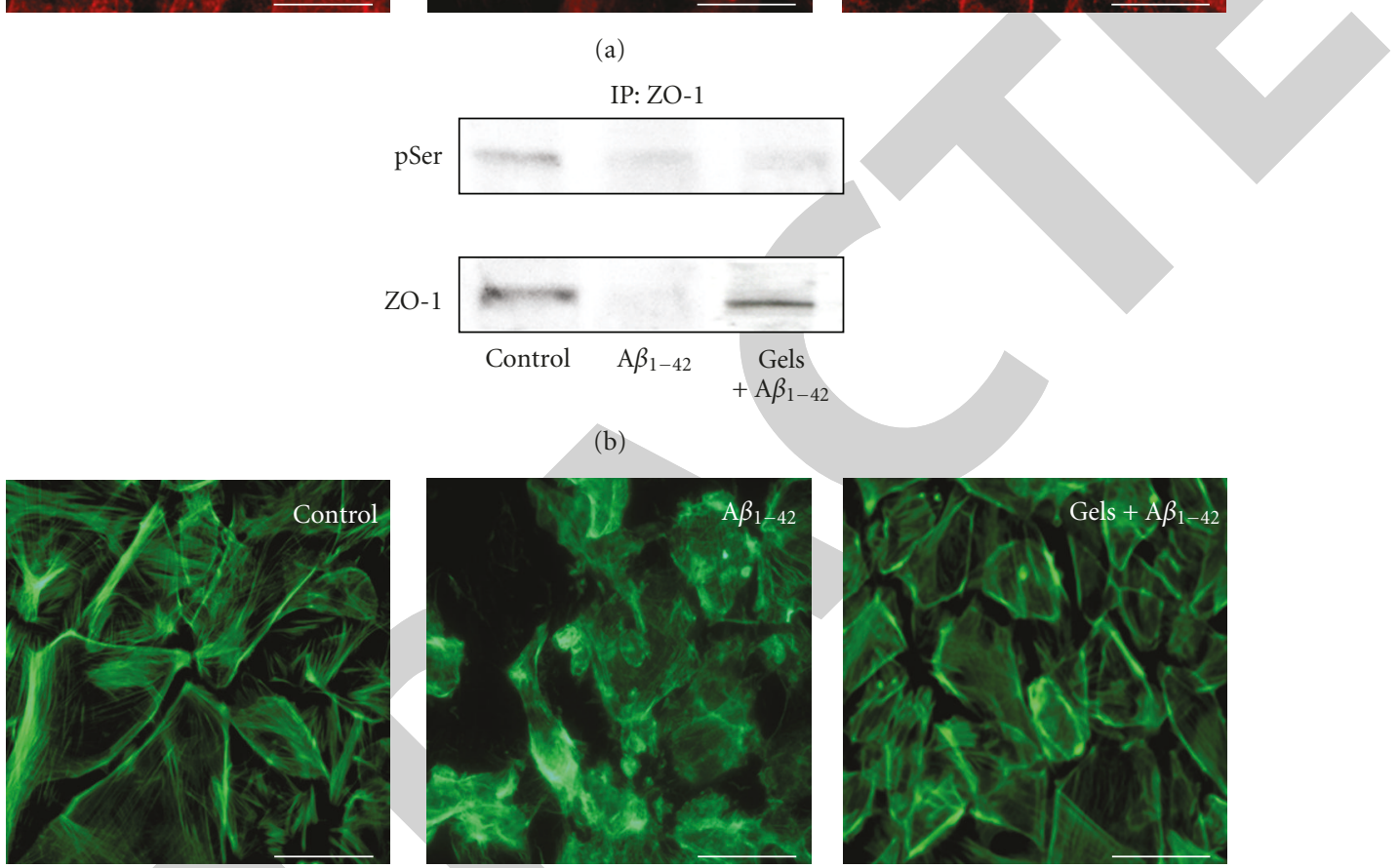

(c)

FIGURE 2: Secreted gelsolin inhibits $A \beta$-induced disruption on choroid plexus epithelial cell cytoskeleton. (a) Representative confocal images of choroid plexus confluent monolayer labeled with anti-ZO-1 antibody. Under control conditions, ZO-1 immunostaining is distributed along the plasma membrane. In contrast, after exposure to $\mathrm{A} \beta_{1-42}$ for 48 hours, a disruption of the plasma membrane pattern of $\mathrm{ZO}-1$ was observed, resulting in increased cytoplasmic localization. Note the ability of gelsolin treatment to prevent this A $\beta$-induced alteration in ZO- 1 pattern. $(n=3)$. (b) $\mathrm{A} \beta_{1-42}$ treatment resulted in increased serine phosphorylation of ZO- 1 and decreased ZO- 1 expression in choroid plexus epithelial cells. Gelsolin coadministration markedly attenuated $\mathrm{A} \beta_{1-42}$ alteration in ZO- $(n=3)$. (c) BIODIPY FL phallacidin staining of choroid plexus epithelial cells showed a disruption of the actin cytoskeleton after treatment with $A \beta_{1-42}$ for 48 hours, and reversion when gelsolin was simultaneously added. Magnification: $\times 40$. Scale bars $=10 \mu \mathrm{m}$.

that the secretory form of gelsolin prevents the internalization of ZO-1 by blocking serine phosphorylation, as has been also demonstrated in other studies [29-31]. The presence of structures characterized by aggregates of polymerized actin (F-actin) has been described in AD [32]. Also, F-actin levels have been shown to increase in hippocampal neurons treated with $A \beta$ [33]. Furthermore, cortical neurons expressing the APP intracellular domain suffer from pronounced changes in the organization of the actin cytoskeleton, including destabilization of actin fibers [34]. We found that fibrillar $\mathrm{A} \beta_{1-42}$ also caused alterations in cytoskeletal actin in choroid plexus epithelial cells, as reflected by an increase in the F-actin content, and that gelsolin was able to protect against this effect. In this way, gelsolin contributes to the maintenance of the choroid plexus monolayer and the bloodCSF barrier integrity. A possible explanation for these effects could be that $A \beta$ increases metalloproteinase $9[11,35$, 36], which is capable of cleaving cytoplasmic gelsolin [37], thereby resulting in the destabilization of actin filaments and the disruption of tight junctions. Secreted gelsolin, which binds and sequestrates $A \beta$, would then be able to prevent and diminish $\mathrm{A} \beta$ toxic effects.

On the other hand, our results also indicate that gelsolin prevents $\mathrm{A} \beta$-induced cell death and $\mathrm{NO}$ production from choroid plexus cell cultures. Using several models of neuronal cell death, others studies have demonstrated that cytoplasmic gelsolin has antiapoptotic properties that correlate with its dynamic actions on the cytoskeleton [38]. 


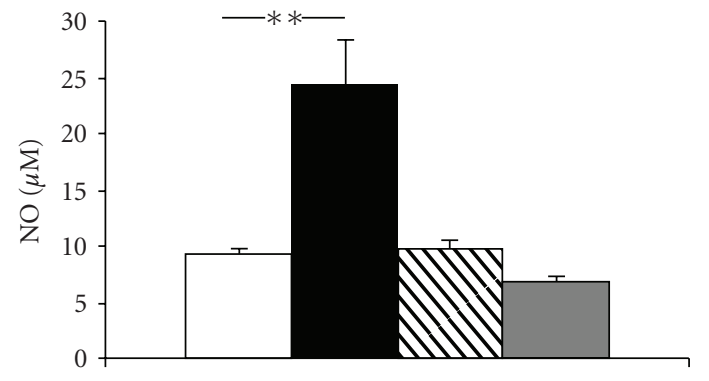

(a)

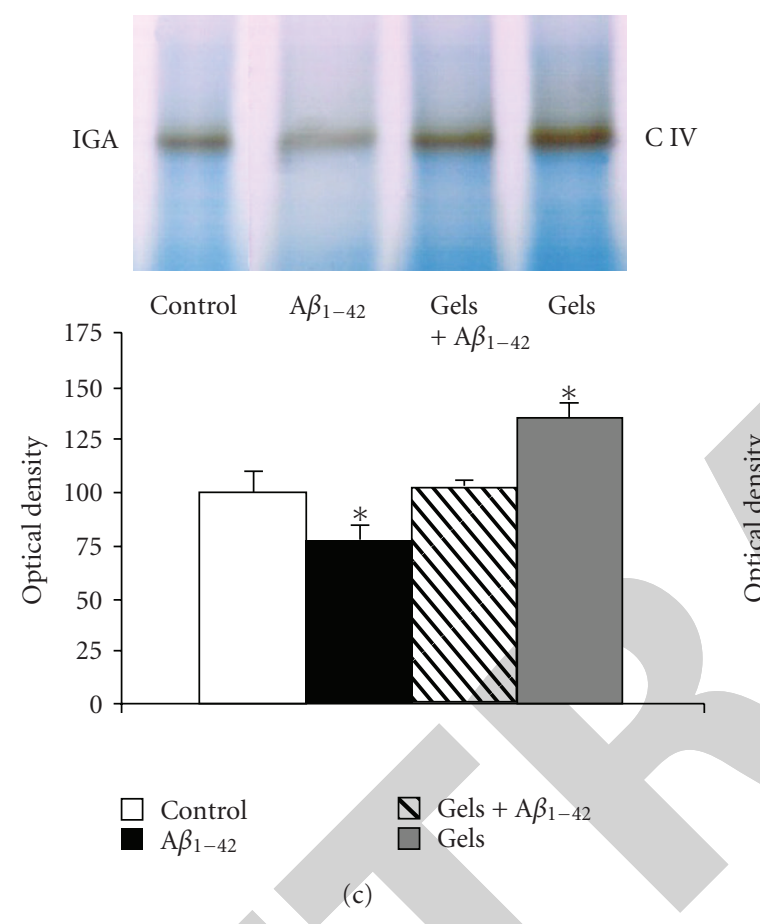

FIGURE 3: Secreted gelsolin expression modulates NO production and cell death in choroid plexus epithelial cells. (a) Choroid plexus epithelial cells treated with $\mathrm{A} \beta_{1-42}$ for 48 hours exhibited a significantly enhanced NO production compared with untreated cells. Secreted gelsolin coadministration completely blocked this effect $(n=3)$; ${ }^{* *} P<.01$. (b) Increased cell death was observed in choroid plexus cell cultures 48 hours after $\mathrm{A} \beta_{1-42}$ treatment, and gelsolin addition totally reversed this toxic effect $(n=3) ;{ }^{*} P<.05$. (c and d) $\mathrm{A} \beta_{1-42}$ treatment reduced mitochondrial complex IV in-gel activity in choroid plexus epithelial cells, whereas secreted gelsolin administration increased complex IV activity and reversed this decrease in $\mathrm{A} \beta_{1-42}$-induced activity. Blue native analysis of these culture samples showed altered protein expression in the mitochondrial complex IV. Representative blue native blots and quantitative histograms are shown $(n=4$ per group); ${ }^{*} P<.05$.

Indeed, gelsolin-null neurons have enhanced cell death [39] and increased vulnerability to glutamate toxicity [40]. In a previous study we reported that $\mathrm{A} \beta$-induced mitochondrial dysfunction could ultimately activate a programmed cell death pathway in the choroid plexus epithelial cells [11]. In this study, we show that secreted gelsolin prevents $\mathrm{A} \beta$-induced cell death by increasing enzyme activity of the respiratory chain complex IV in the choroid plexus epithelial cells. These observations are in line with other studies showing an $\mathrm{A} \beta$-induced reduction of mitochondrial membrane potential by cytoplasmic gelsolin $[41,42]$. The intracellular form of gelsolin is associated to the mitochondrial membrane, where it can inhibit $\mathrm{A} \beta$-induced loss of mitochondrial membrane potential, cytochrome c release,
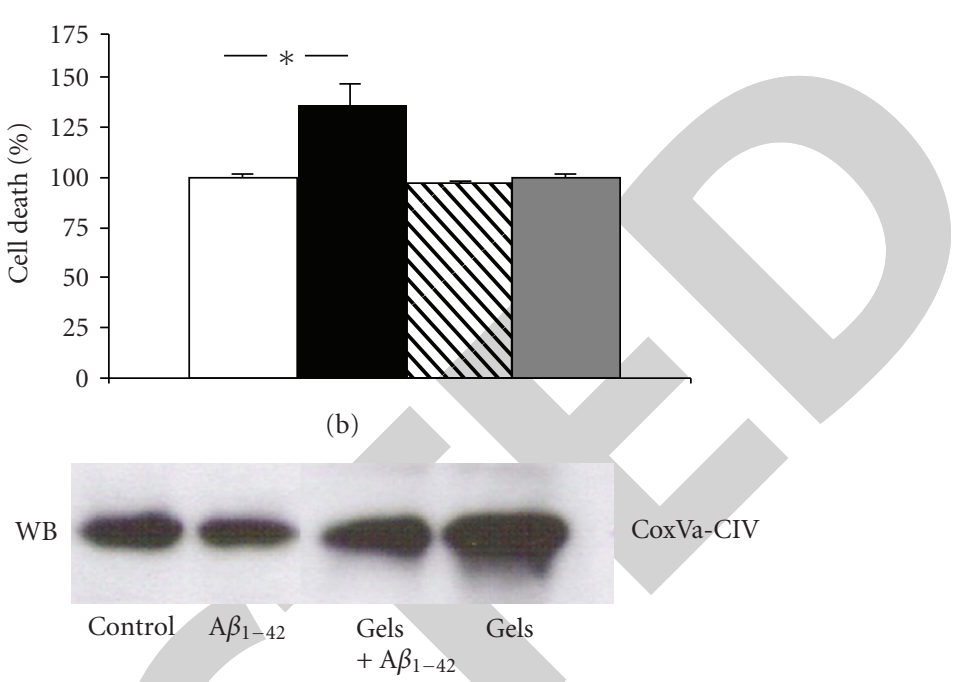

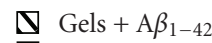

Gels

(d) and regulate voltage-dependent channels [40, 41]. Since extracellular gelsolin has also been detected in CSF, where its concentration is significantly altered in certain neurological conditions [43], this extracellular isoform of gelsolin may well reduce choroid plexus $\mathrm{A} \beta$-induced pathology in a similar manner to intracellular gelsolin $[17,18]$.

In conclusion, our results demonstrate that secreted gelsolin can modulate $\mathrm{A} \beta$-induced alterations in the bloodCSF barrier. We suggest that secreted gelsolin have a neuroprotective role against $\mathrm{A} \beta$ neurotoxicity. In summary, enhancement of gelsolin levels may represent a novel way to protect against $A \beta$ neurotoxicity and, in the future, could be considered a potential therapeutic strategy for the treatment of patients with $\mathrm{AD}$. 


\section{Acknowledgments}

This work was supported by Grants from Fondo de Investigacion Sanitaria (FIS) (CP04/00179, PI060155) and Fundación Investigación Médica Mutua Madrileña (2006.125) and (CP04/00011, PI050379) to CU. The authors thank Dr. Ximena Alvira for her editorial assistance.

\section{References}

[1] D. J. Selkoe, "The deposition of amyloid proteins in the aging mammalian brain: implications for Alzheimer's disease," Annals of Medicine, vol. 21, no. 2, pp. 73-76, 1989.

[2] D. J. Selkoe, “Toward a comprehensive theory for Alzheimer's disease. Hypothesis: Alzheimer's disease is caused by the cerebral accumulation and cytotoxicity of amyloid $\beta$-protein," Annals of the New York Academy of Sciences, vol. 924, pp. 17$25,2000$.

[3] M. F. Knauer, B. Soreghan, D. Burdick, J. Kosmoski, and C. G. Glabe, "Intracellular accumulation and resistance to degradation of the Alzheimer amyloid A4/ $\beta$ protein," Proceedings of the National Academy of Sciences of the United States of America, vol. 89, no. 16, pp. 7437-7441, 1992.

[4] C. Glabe, "Intracellular mechanisms of amyloid accumulation and pathogenesis in Alzheimer's disease," Journal of Molecular Neuroscience, vol. 17, no. 2, pp. 137-145, 2001.

[5] M. O. Dietrich, C. Spuch, D. Antequera, et al., "Megalin mediates the transport of leptin across the blood-CSF barrier," Neurobiology of Aging, vol. 29, no. 6, pp. 902-912, 2008.

[6] R. N. Kalaria, "The blood-brain barrier and cerebrovascular pathology in Alzheimer's disease," Annals of the New York Academy of Sciences, vol. 893, pp. 113-125, 1999.

[7] T. Miyakawa, T. Kimura, S. Hirata, et al., "Role of blood vessels in producing pathological changes in the brain with Alzheimer's disease," Annals of the New York Academy of Sciences, vol. 903, pp. 46-54, 2000.

[8] R. Deane and B. V. Zlokovic, "Role of the blood-brain barrier in the pathogenesis of Alzheimer's disease," Current Alzheimer Research, vol. 4, no. 2, pp. 191-197, 2007.

[9] F. J. Gonzalez-Velasquez, J. A. Kotarek, and M. A. Moss, "Soluble aggregates of the amyloid- $\beta$ protein selectively stimulate permeability in human brain microvascular endothelial monolayers," Journal of Neurochemistry, vol. 107, no. 2, pp. 466-477, 2008.

[10] S. Marco and S. D. Skaper, "Amyloid $\beta$-peptide1-42 alters tight junction protein distribution and expression in brain microvessel endothelial cells," Neuroscience Letters, vol. 401, no. 3, pp. 219-224, 2006.

[11] T. Vargas, C. Ugalde, C. Spuch, et al., "A $\beta$ accumulation in choroid plexus is associated with mitochondrial-induced apoptosis," Neurobiology of Aging. 2008 Oct 4. [Epub ahead of print].

[12] N. Matsumoto, H. Kitayama, M. Kitada, K. Kimura, M. Noda, and C. Ide, "Isolation of a set of genes expressed in the choroid plexus of the mouse using suppression subtractive hybridization," Neuroscience, vol. 117, no. 2, pp. 405-415, 2003.

[13] H. Q. Sun, M. Yamamoto, M. Mejillano, and H. L. Yin, "Gelsolin, a multifunctional actin regulatory protein," The Journal of Biological Chemistry, vol. 274, no. 47, pp. 3317933182, 1999.

[14] D. J. Kwiatkowski, T. P. Stossel, and S. H. Orkin, "Plasma and cytoplasmic gelsolins are encoded by a single gene and contain a duplicated actin-binding domain," Nature, vol. 323, no. 6087 , pp. $455-458,1986$.

[15] V. P. S. Chauhan, I. Ray, A. Chauhan, and H. M. Wisniewski, "Binding of gelsolin, a secretory protein, to amyloid $\beta$ protein," Biochemical and Biophysical Research Communications, vol. 258, no. 2, pp. 241-246, 1999.

[16] I. Ray, A. Chauhan, J. Wegiel, and V. P. S. Chauhan, "Gelsolin inhibits the fibrillization of amyloid $\beta$-protein, and also defibrillizes its preformed fibrils," Brain Research, vol. 853, no. 2, pp. 344-351, 2000.

[17] Y. Matsuoka, M. Saito, J. LaFrancois, et al., "Novel therapeutic approach for the treatment of Alzheimer's disease by peripheral administration of agents with an affinity to $\beta$-amyloid," Journal of Neuroscience, vol. 23, no. 1, pp. 29-33, 2003.

[18] A. C. Hirko, E. M. Meyer, M. A. King, and J. A. Hughes, "Peripheral transgene expression of plasma gelsolin reduces amyloid in transgenic mouse models of Alzheimer's disease," Molecular Therapy, vol. 15, no. 9, pp. 1623-1629, 2007.

[19] E. Carro, J. L. Trejo, T. Gomez-Isla, D. LeRoith, and I. TorresAleman, "Serum insulin-like growth factor I regulates brain amyloid- $\beta$ levels," Nature Medicine, vol. 8, no. 12, pp. 13901397, 2002.

[20] L. G. Nijtmans, N. S. Henderson, and I. J. Holt, "Blue Native electrophoresis to study mitochondrial and other protein complexes," Methods, vol. 26, no. 4, pp. 327-334, 2002.

[21] T. P. Stossel, "Actin-membrane interactions in eukaryotic mammalian cells," in Current Topis in Membranes and Transport, J. F. Hoffman and G. Giebisch, Eds., pp. 97-107, Academic Press, New York, NY, USA, 1990.

[22] L. Ji, A. Chauhan, and V. Chauhan, "Cytoplasmic gelsolin in pheochromocytoma- 12 cells forms a complex with amyloid $\beta$ protein," NeuroReport, vol. 19, no. 4, pp. 463-466, 2008.

[23] B. V. Zlokovic, C. L. Martel, E. Matsubara, et al., "Glycoprotein 330/megalin: probable role in receptor-mediated transport of apolipoprotein J alone and in a complex with Alzheimer disease amyloid $\beta$ at the blood-brain and blood-cerebrospinal fluid barriers," Proceedings of the National Academy of Sciences of the United States of America, vol. 93, no. 9, pp. 4229-4234, 1996.

[24] E. Carro, C. Spuch, J. L. Trejo, D. Antequera, and I. TorresAleman, "Choroid plexus megalin is involved in neuroprotection by serum insulin-like growth factor I," Journal of Neuroscience, vol. 25, no. 47, pp. 10884-10893, 2005.

[25] R. Deane, Z. Wu, A. Sagare, et al., "LRP/amyloid $\beta$-peptide interaction mediates differential brain efflux of $A \beta$ isoforms," Neuron, vol. 43, no. 3, pp. 333-344, 2004.

[26] S. M. Hammad, S. Ranganathan, E. Loukinova, W. O. Twal, and W. S. Argraves, "Interaction of apolipoprotein J-amyloid $\beta$-peptide complex with low density lipoprotein receptor-related protein-2/megalin. A mechanism to prevent pathological accumulation of amyloid $\beta$-peptide," The Journal of Biological Chemistry, vol. 272, no. 30, pp. 18644-18649, 1997.

[27] C. V. Zerbinatti, D. F. Wozniak, J. Cirrito, et al., "Increased soluble amyloid- $\beta$ peptide and memory deficits in amyloid model mice overexpressing the low-density lipoprotein receptor-related protein," Proceedings of the National Academy of Sciences of the United States of America, vol. 101, no. 4, pp. 1075-1080, 2004.

[28] E. I. Christensen and H. Birn, "Megalin and cubilin: multifunctional endocytic receptors," Nature Reviews Molecular Cell Biology, vol. 3, no. 4, pp. 256-266, 2002.

[29] K. Ohtake, T. Maeno, H. Ueda, M. Ogihara, H. Natsume, and Y. Morimoto, "Poly-L-arginine enhances paracellular 
permeability via serine/threonine phosphorylation of ZO-1 and tyrosine dephosphorylation of occludin in rabbit nasal epithelium," Pharmaceutical Research, vol. 20, no. 11, pp. 1838-1845, 2003.

[30] N. T. Collins, P. M. Cummins, O. C. Colgan, et al., "Cyclic strain-mediated regulation of vascular endothelial occludin and ZO-1: influence on intercellular tight junction assembly and function," Arteriosclerosis, Thrombosis, and Vascular Biology, vol. 26, no. 1, pp. 62-68, 2006.

[31] H. Rincon-Choles, T. L. Vasylyeva, P. E. Pergola, et al., "ZO1 expression and phosphorylation in diabetic nephropathy," Diabetes, vol. 55, no. 4, pp. 894-900, 2006.

[32] P. H. Gibson and B. E. Tomlinson, "Numbers of Hirano bodies in the hippocampus of normal and demented people with Alzheimer's disease," Journal of the Neurological Sciences, vol. 33, no. 1-2, pp. 199-206, 1977.

[33] A. Mendoza-Naranjo, C. Gonzalez-Billault, and R. B. Maccioni, "A $\beta 1-42$ stimulates actin polymerization in hippocampal neurons through Rac1 and Cdc42 Rho GTPases," Journal of Cell Science, vol. 120, no. 2, pp. 279-288, 2007.

[34] T. Müller, C. G. Concannon, M. W. Ward, et al., "Modulation of gene expression and cytoskeletal dynamics by the amyloid precursor protein intracellular domain (AICD)," Molecular Biology of the Cell, vol. 18, no. 1, pp. 201-210, 2007.

[35] J.-M. Lee, K.-J. Yin, I. Hsin, et al., "Matrix metalloproteinase-9 and spontaneous hemorrhage in an animal model of cerebral amyloid angiopathy," Annals of Neurology, vol. 54, no. 3, pp. 379-382, 2003.

[36] A. A. Talamagas, S. Efthimiopoulos, E. C. Tsilibary, M. E. Figueiredo-Pereira, and A. K. Tzinia, "A $\beta(1-40)$-induced secretion of matrix metalloproteinase- 9 results in sAPP $\alpha$ release by association with cell surface APP," Neurobiology of Disease, vol. 28, no. 3, pp. 304-315, 2007.

[37] G. Candiano, M. Bruschi, N. Pedemonte, et al., "Gelsolin secretion in interleukin-4-treated bronchial epithelia and in asthmatic airways," American Journal of Respiratory and Critical Care Medicine, vol. 172, no. 9, pp. 1090-1096, 2005.

[38] C. Harms, J. Bösel, M. Lautenschlager, et al., "Neuronal gelsolin prevents apoptosis by enhancing actin depolymerization," Molecular and Cellular Neuroscience, vol. 25, no. 1, pp. 69-82, 2004.

[39] M. Endres, K. Fink, J. Zhu, et al., "Neuroprotective effects of gelsolin during murine stroke," Journal of Clinical Investigation, vol. 103, no. 3, pp. 347-354, 1999.

[40] K. Furukawa, W. Fu, Y. Li, W. Witke, D. J. Kwiatkowski, and M. P. Mattson, "The actin-severing protein gelsolin modulates calcium channel and NMDA receptor activities and vulnerability to excitotoxicity in hippocampal neurons," Journal of Neuroscience, vol. 17, no. 21, pp. 8178-8186, 1997.

[41] R. C. Koya, H. Fujita, S. Shimizu, et al., "Gelsolin inhibits apoptosis by blocking mitochondrial membrane potential loss and cytochrome c release," The Journal of Biological Chemistry, vol. 275, no. 20, pp. 15343-15349, 2000.

[42] H. Qiao, R. C. Koya, K. Nakagawa, et al., "Inhibition of Alzheimer's amyloid- $\beta$ peptide-induced reduction of mitochondrial membrane potential and neurotoxicity by gelsolin," Neurobiology of Aging, vol. 26, no. 6, pp. 849-855, 2005.

[43] A. Kulakowska, W. Drozdowski, A. Sadzynski, R. Bucki, and P. A. Janmey, "Gelsolin concentration in cerebrospinal fluid from patients with multiple sclerosis and other neurological disorders," European Journal of Neurology, vol. 15, no. 6, pp. 584-588, 2008. 